\title{
1-1-16 高度蜼聴胃《対才子補㯖置適合。諸问題。
}

\section{○安野友博。河开紀子、井端幸子（宗府医大耳）}

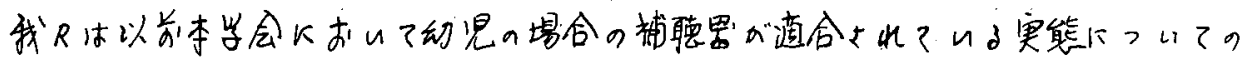

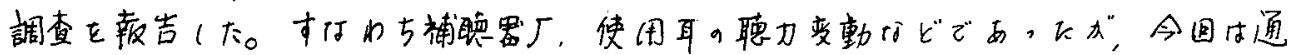

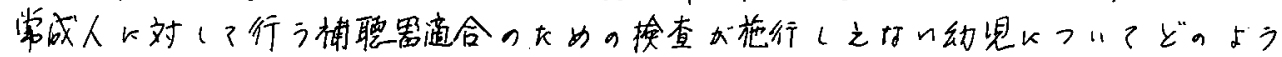

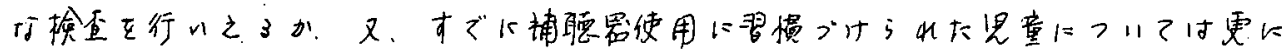

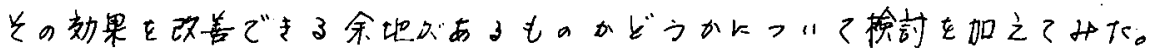

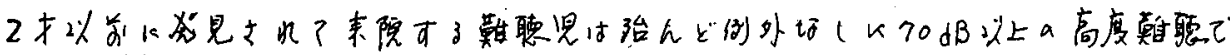

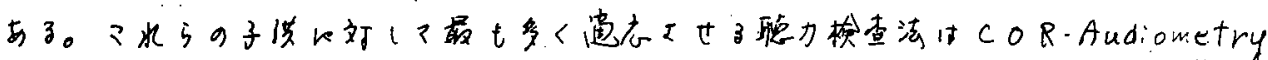

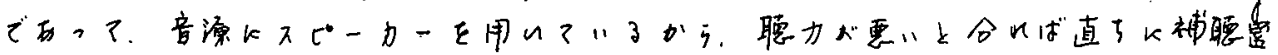

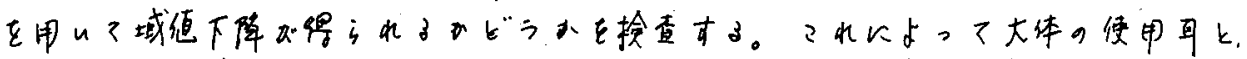

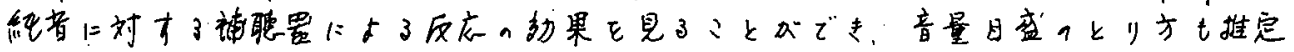

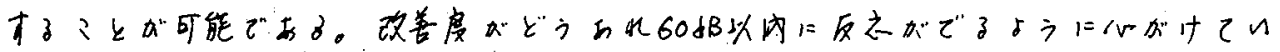

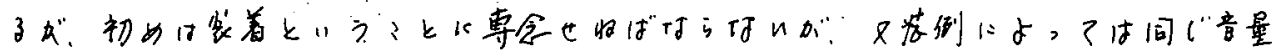

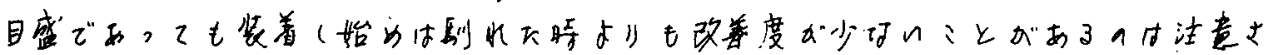

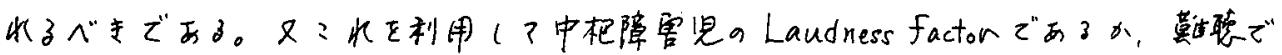

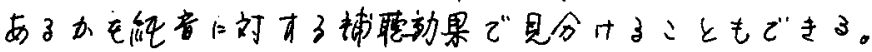

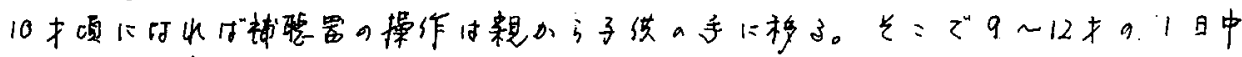

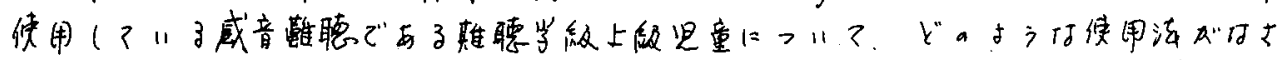

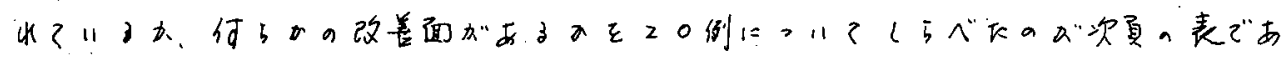

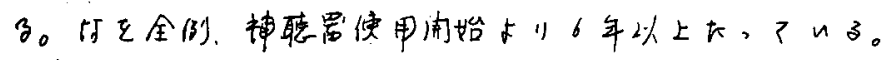

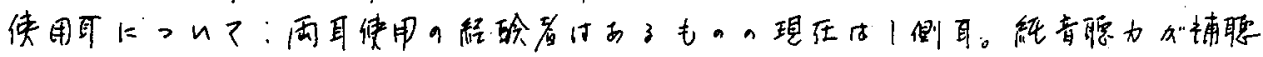

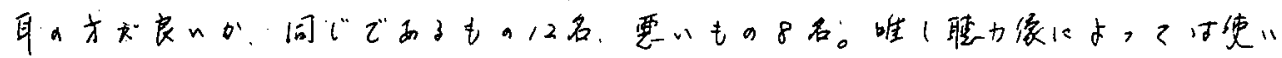

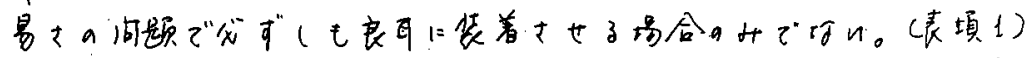

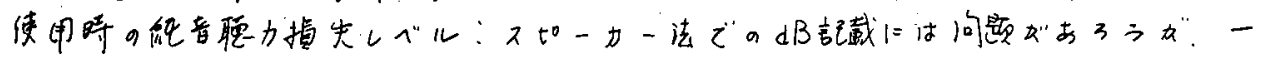

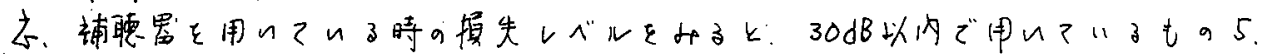

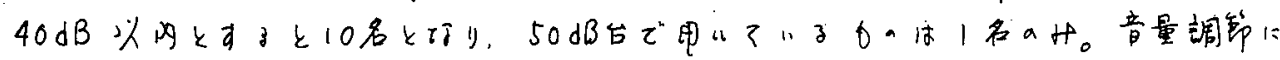

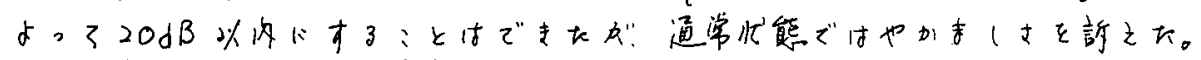

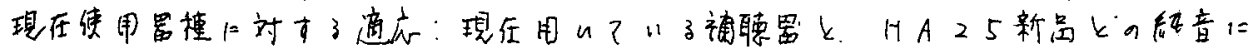

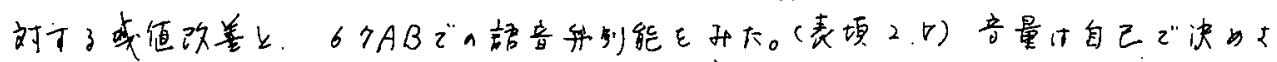

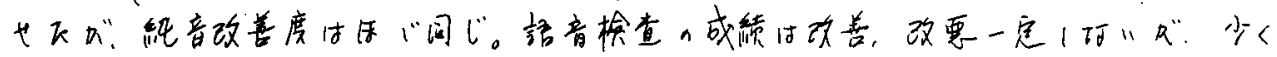

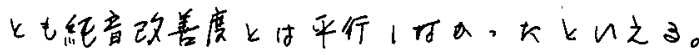

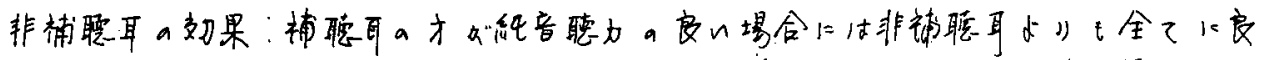

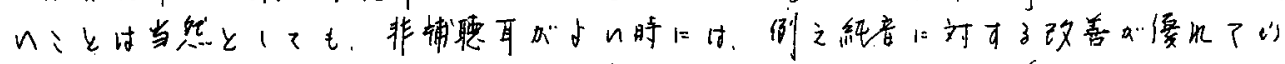

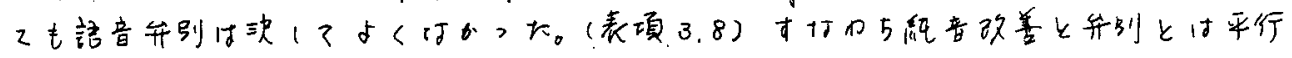

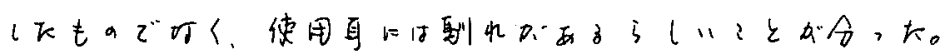

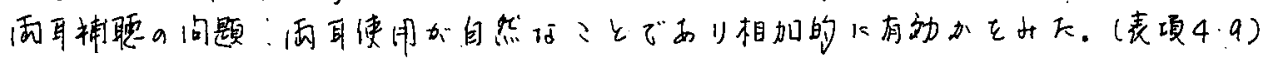




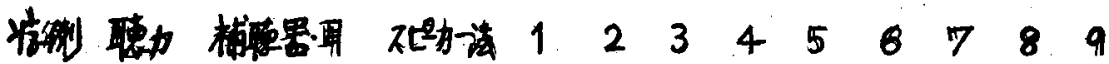

\section{右左AB}

1. $89.83 \mathrm{HAH} \cdot$ 左

273.75 HA2T. 左

374.78 RH55. 右

$478 \cdot 75$ HAI3. 古

588.85 Vocal. 右

693.93 Otic. 左

$7 \quad 74.78$ HA.13 右

$880.86 \quad X-r$. 右

$981.74 \quad x-r$. 左

$10 \quad 84.79 \quad x-r$. 右

$1182.88 \quad x-r . \quad$ 石

$1275 \cdot \pi 1 \cdot M A B \cdot{ }^{2}$

1376.78 HAI3. 右

$1488.88 \quad X-r$ 左

1578.64 RH $55 \cdot$ 右

$16 \quad 89.76 \quad H A 25 \cdot$ 右

$1773.75^{\circ} \mathrm{RH} 55^{\circ} \cdot$ 右

$18 \quad 43.58$ MA.06. 右

1981.83 Vocal. 左

2084.71 otic. 左 $d B \quad d B \quad d B \quad d B \quad d B \quad d B \quad \% \quad \% \quad \%$

$\begin{array}{lllllllllll}75 & 48 & 40 & 55 & 41 & 65 & 50 & 20 & 45 & 35\end{array}$

$\begin{array}{llllllllll}68 & 59 & 38 & 55 & 31 & 30 & 65 & 70 & 55 & 65\end{array}$

$\begin{array}{llllllllll}61 & 30 & 36 & 40 & 18 & 45 & 70 & 55 & 25 & 70\end{array}$

$\begin{array}{lllllllllll}63 & 45 & 40 & 46 & 44 & 45 & 65 & 85 & 55 & 50\end{array}$

$\begin{array}{llllllllll}80 & 24 & 35 & 44 & 34 & 55 & 5 & 0 & 0 & 5\end{array}$

$\begin{array}{llllllllll}88 & 43 & 49 & 45 & 41 & 60 & 5 & 0 & 0 & 0\end{array}$

76. $3945 / 36429080 / 90$

$7845 \quad 39 / 3848 \quad 6535 / 60$

$\begin{array}{llllllllll}75 & 20 & 28 & 44 & 21 & 40 & 45 & 30 & 10 & 55\end{array}$

$\begin{array}{llllllllll}73 & 31 & 36 & 35 & 31 & 40 & 50 & 50 & 15 & 45\end{array}$

$\begin{array}{llllllllll}76 & 45 & 29 & 29 & 28 & 55 & 20 & 10 & 0 & 10\end{array}$

$\begin{array}{llllllllll}73 & 44 & 35 & 26 & 23 & 45 & 65 & 75 & 25 & 80\end{array}$

$\begin{array}{llllllllll}79 & 49 & 51 & 55 & 49 & 45 & 55 & 30 & 35 & 35\end{array}$

$\begin{array}{lllllllllll}84 & 38 & 54 & 63 & 41 & 55 & 10 & 10 & 5 & 0\end{array}$

$\begin{array}{llllllllll}55 & 24 & 35 & 36 & 24 & 35 & 80 & 75 & 80 & 65\end{array}$

$\begin{array}{llllllllll}78 & 35 & 35 & 39 & 30 & 40 & 60 & 60 & 35 & 60\end{array}$

$\begin{array}{llllllllll}63 & 46 & 31 & 30 & 33 & 35 & 40 & 60 & 50 & 60\end{array}$

$\begin{array}{llllllllll}44 & 30 & 13 & 24 & 4 & 20 & 15 & 65 & 20 & 35\end{array}$

$\begin{array}{lllllllllll}80 & 46 & 44 & 51 & 34 & 45 & 45 & 20 & 10 & 35\end{array}$

$\begin{array}{llllllllll}71 & 32 & 32 & 19 & 15 & 30 & 75 & 75 & 55 & 55\end{array}$

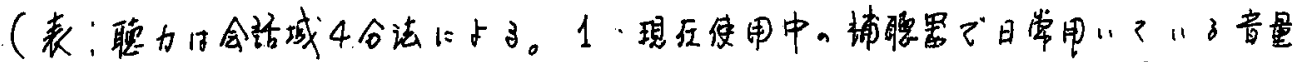

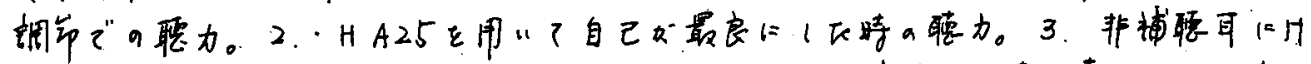

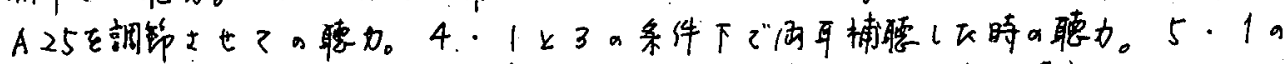

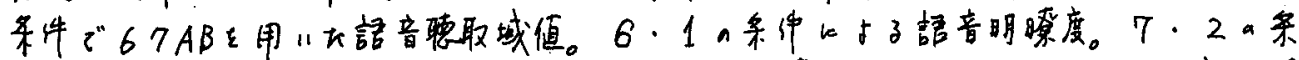

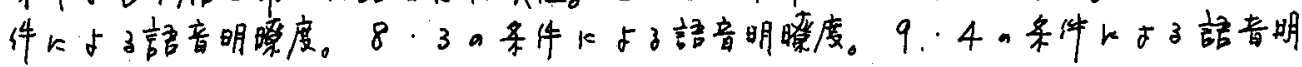
蹽度度。)

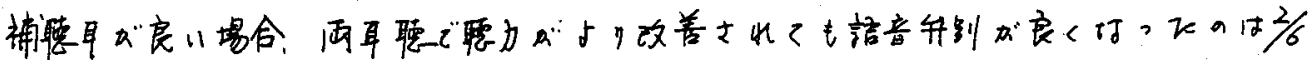

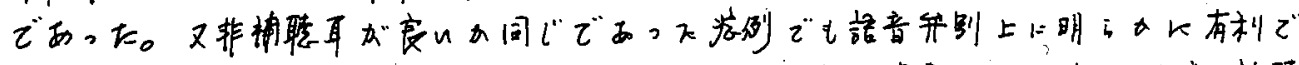

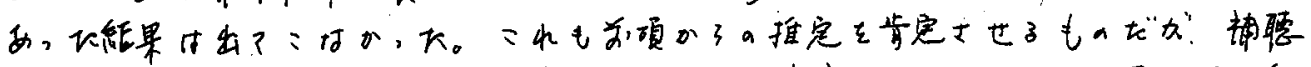

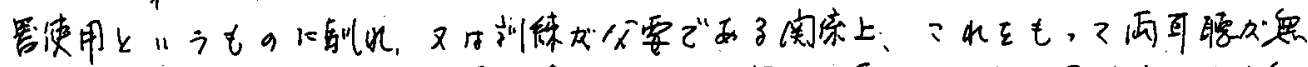

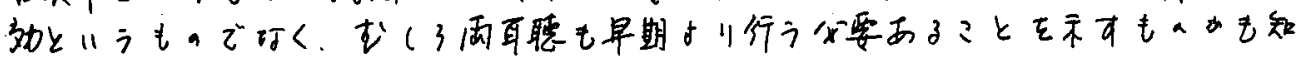
九败的。

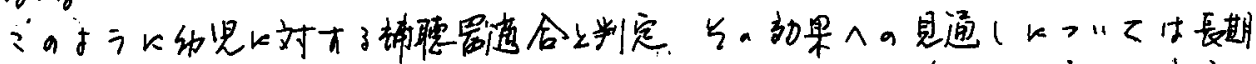

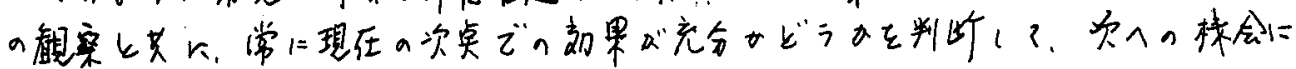

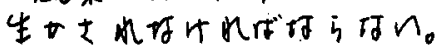

